\title{
Participatory Gender Analysis of Sorghum Value Chain: the Case of Konso District, Ethiopia Implication for Sorghum Research Improvement
}

\begin{abstract}
Abayneh Feyso $^{1 *}$, Selamawit Markos ${ }^{2}$, Awoke Mensa ${ }^{2}$
${ }^{1 *}$ Lecturer and Researcher, Department of Agri business and Value Chain Management, Arbaminch University

${ }^{2}$ Researcher, Southern Agricultural Research Institute, Arbaminch center, Ethiopia

*abay.fa2014@gmail.com

Abstract: This study was designed to analyze gender role in sorghum production and processing in the case of Konso District with specific objectives to identify gender role for sorghum production and processing, to identify gender labor contribution for sorghum production and to identify sorghum production and utilization constraints and gender preferences for sorghum. Qualitative data collection and analysis method was employed to achieve aforementioned research objectives. Sex-segregated FGDs held and helped women and men felt free to share their perspectives on gendered culture. Data were analyzed using participatory qualitative data analysis method. The analysis result shows that around $90 \%$ male headed house hold and $100 \%$ female headed and polygamy women do not get any sorghum production related trainings. Data analysis result indicates that apart from the household chores, working in the farm is the responsibility of the Konso women. Men in Konso testify that "our women are very strong and hardworking." Also the result indicated that female headed households have limited access to and control over resources, which is crucial to effectively and efficiently meeting their strategic and practical needs due to social and cultural biases in the society. Women in Konso spend more than 15 hours a day performing the household activities, but men spent only around 8 hours a day. Due to cultural taboos and believes, community work and public decision-making activities are areas, in which women do not have an active participation.

In Konso sorghum grain is consumed in different forms of food items like Cheqa, kurkufa, genfo and qita. Only two improve sorghum variety were introduced and around 95\% farmers are using local varieties and each variety has its own local name and preference of utilization. Food security is hot issues of farming communities of Konso and they get high food shortage during April to August every production year.
\end{abstract}

Keywords: Konso, sorghum, gender, male headed, female headed

\section{INTRODUCTION}

Sorghum is the fifth most important cereal globally and the dietary staple of around 500 million people. It is an important food crop in many parts of eastern and southern Africa. Sorghum is tolerant, relative to other major cereal crops, to adverse growing conditions. Some early-maturing sorghum cultivars require less than two months of rainfall to produce grain, and the species is genetically very diverse with preferred cultivars for different uses [2]. Ethiopia is the $2^{\text {nd }}$ largest producer of Sorghum in Africa and globally ranks $6^{\text {th }}$ in production (3.6MMT), $5^{\text {th }}$ in area harvested (1.7 MM Ha), but $34^{\text {th }}$ in yield $(2.1 \mathrm{MT} / \mathrm{Ha})$. Sorghum is the single most important cereal in drought prone areas which is serves as food security crop because sorghum is a resilient crop requiring less than $600 \mathrm{~mm}$ annual rainfall [3] 
Participatory Gender Analysis of Sorghum Value Chain: the Case of Konso District, Ethiopia Implication for Sorghum Research Improvement

Konso district is characterized by rugged and stony soil. The main agricultural area ranges from $1400 \mathrm{~m}$ to $2000 \mathrm{~m}$ above sea level. Sorghum is the staple crop of the Konso and is said to be ancient in the district. A wide spectrum of varieties has been found and at least 24 cultivars are named and distinguished by farmers [4]. Sorghum forms the basic diet of the Konso, seeds are ground, the flour formed into balls (called kurkufa) and then cooked in water and they make drink from flour called Cheqa while Labor division in Konso is more egalitarian. Men and women often work together in the fields, but the main labor burden falls on the women [9]. Activities like terracing, building, fencing and dispute settling were done by men whereas collecting water, carrying, looking after children, cooking, grinding, collecting firewood, fetching water, brewing Cheqa were done by female. Also digging, sowing, weeding, harvesting, scaring birds, looking after animals, were performed jointly by male and female, but the level of gender labor contribution for sorghum production, processing and utilization were not known therefore this study was designed to analyze gender role in sorghum production and processing in the case of Konso District with Specific objectives To identify gender role for sorghum production and processing, to identify gender labor contribution for sorghum production and to identify sorghum production and utilization constraints and gender preferences for sorghum.

\section{RESEARCH Methodology}

\section{Description of Study Area}

Konso district is one among the five districts of segen people's zone, occupying area of $650 \mathrm{~km}^{2}$ and located at $700 \mathrm{~km}$ south of Addis Ababa. The main agricultural area ranges from $1400 \mathrm{~m}$ to $2000 \mathrm{~m}$ above sea level. Temperature varies from $15^{\circ} \mathrm{C}$ to $33^{\circ} \mathrm{C}$. Rainfall distribution follows a bimodal pattern. Average total annual rainfall is only $551 \mathrm{~mm}$, with annual rainfall variation between $300 \mathrm{~mm}$ and $900 \mathrm{~mm}$. The rains are split into two rainy seasons. The big rains are concentrated at the end of February until May and the small rains occur around October and November. They practice an integrated crop-livestock system. Konso farmers are known by art of terracing. The terraces cover hillsides over hundreds of kilometers and over a height of $700 \mathrm{~m}$, which is built with stonewalls. The main function of this structure is to maximize water retention, infiltration and preventing soil erosion. They keep cattle, goats, sheep and sometimes chickens and donkeys. Cattle are either kept on pastures in the lowlands or on uncultivated areas near the periphery of the villages. But the largest number of the livestock is kept in stables in the homesteads. The animals are fed stalks of sorghum and maize or the leaves of trees planted in part for this purpose.

Konso district is densely populated and population is growing rapidly. The pressure on land is increasing, resulting in marginal lands to be taken into production and problems resulting from overstressing the farming system. The erratic climate and harsh conditions make agriculture in the region very difficult.

Traditionally, the Konso were monogamous, but now Konso can have three or four wives. Their social-economic system divides their society into two groups: Ententa and Xauta. Generally the Ententa are farmers and the Xauta are artisans, including hide workers. Membership in Ententa and Xauta is ascribed at birth [6].

The Konso are organized in nine exogamous clans: Keertitta, Arkaamayta, Sawdatta, Paasanta, Tookmaleeta, Eelayta, Ifalayta, Tikissayta and Mahalayta. Except for the Keertitta clan, each clan has its own chief [8].

\section{Design of the Study}

Among sorghum producer Kebeles of Konso district three clusters namely: Fasha cluster, Karat zuria a cluster and Arifeyide cluster were selected purposively after consulting with District agriculturalists due to their sorghum production potential and agro-ecology inclusion. Finally from each cluster one kebele: Kamele kebele 
Participatory Gender Analysis of Sorghum Value Chain: the Case of Konso District, Ethiopia Implication for Sorghum Research Improvement

from Fasha cluster, Arifeide kebele from Arifeide cluster and Sorobo Kebele from Karat zuria cluster were selected randomly. Then, sorghum producers of selected kebeles were stratified based on household head and marriage type in to three strata; namely: Male headed household, ${ }^{1}$ female headed house hold and polygamy marriage. Among each stratus 10 and totally 90 household heads were selected randomly and participated in the focus group discussion. Focus group discussions were held separately with male headed households, female headed households and polygamy married females.

Qualitative data were collected from FGD participants using check list. One of strengths of this gender analysis field work is that sex-segregated FGDs helped women and men felt free to share their perspectives on gendered cultural and social stereotypes. To strengthen primary data collected via FGD from participants key informant interview was held with district Farm and Natural Resource development office heads and extension expertise, women and youth affair office heads and expertise, tourism and culture development office head and expertise and kebele level extension and development agents.

Finally collected data were analyzed using qualitative data analysis methods like pair-wise ranking, proportional pilling and direct matrix ranking participatory.
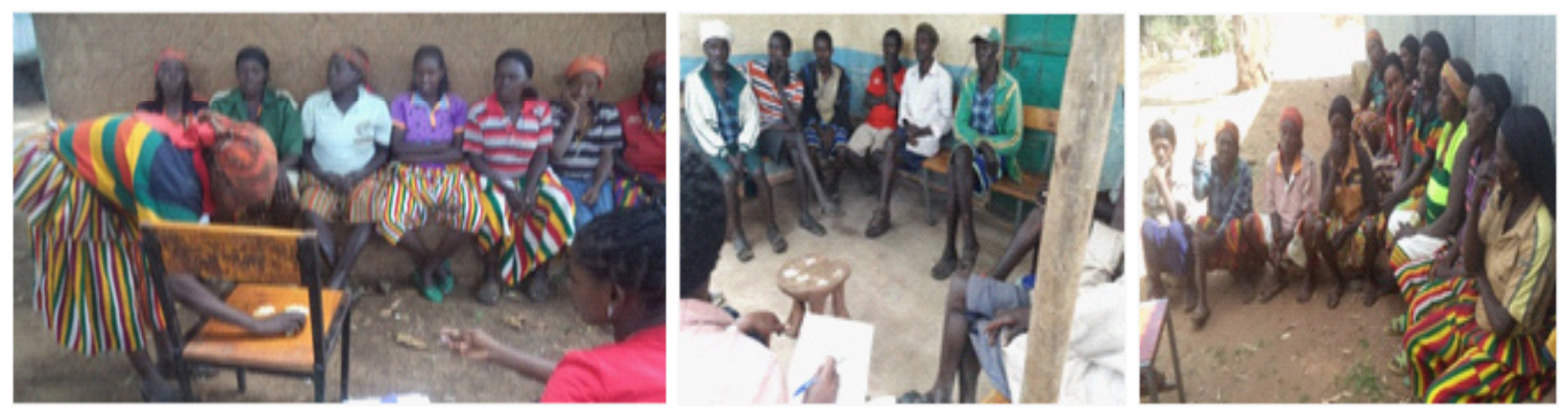

Figure focus group discussion participants and women at proportional pilling

\section{RESUlTS AND DisCUSSION}

\section{Participation of Women and Men in Sorghum Production}

The agricultural cycle is very much dependent on rainfall. Land preparations start with the first rains in January. Generally, the fields are only worked on once before sowing. Sowing starts as soon as the big rains begin in February. Cereals (sorghum and maize) and pulses are broadcasted in a seed mixture. An extensive period of weeding and scaring off birds follows. Harvest takes place in the dry months in May onwards, first roots and tubers, then cereals and pulses, finally in mid-September sorghum. The harvested grain is stored in granaries and selected heads are hung in the houses for next season seed. Men and women in Konso often work together in the fields, but the main labor burden falls on the women [9].

Farming in Konso, as elsewhere in other parts of Africa, is said to be men's activity. Even if, it is said to be men's work, women do the majority of the farm work in Konso. Konso Women do more than $95 \%$ of the farm work. The women in Konso are involved in digging, planting, weeding, harvesting, transporting and storage activities. It is only at the stage of storing that men have the relatively greater share. At this stage, the women would assist them carrying the product to the granary and the men performed the accumulation activity [7].

1. Female headed household is defined as a household in which a male decision maker is absent. Female headed household is one in which the woman owns the land and makes all decisions (e.g., widows, divorced women and single mothers). 
Participatory Gender Analysis of Sorghum Value Chain: the Case of Konso District, Ethiopia Implication for Sorghum Research Improvement

Table1. Productive activities and labor contribution for sorghum production ${ }^{2}$

\begin{tabular}{|c|c|c|c|c|}
\hline \multirow[b]{2}{*}{$\begin{array}{c}\text { Productive activities } \\
\text { Land preparation }\end{array}$} & \multicolumn{4}{|c|}{ Labor contribution in gender } \\
\hline & Women (\%) & Girls (\%) & Men (\%) & Boys (\%) \\
\hline Plowing using oxen & 0 & 0 & 64 & 36 \\
\hline Digging using double-bladed hand hoe & 28 & 12 & 38 & 22 \\
\hline Sowing & 25 & 0 & 43 & 32 \\
\hline Weeding & 21 & 29 & 19 & 31 \\
\hline Fertilizer application & 0 & 0 & 62 & 38 \\
\hline Bird-scaring & 0 & 69 & 0 & 31 \\
\hline Harvesting & 17 & 34 & 19 & 30 \\
\hline Transporting harvest grain from field & 19 & 41 & 19 & 33 \\
\hline Threshing & 66 & 34 & 0 & 0 \\
\hline Winnowing & 66 & 34 & 0 & 0 \\
\hline
\end{tabular}

Source: survey result, 2017

As proportional pilling result indicates in (Table 1) above and (Table 2) below apart from the household chores, working in the farm is the responsibility of the Konso women. In the morning after fetching water, they tending the cattle and serving breakfast in the house, the women go to the field for weeding, and digging till late in the afternoon. Then, they collect firewood and fodder for the cattle and return home to prepare dinner for the family. Except plowing using oxen (64\% done by men and 36 was done by boys) and fertilizer application (62\% was done by men and $38 \%$ by boys) women play key role and carry major activities of field management and sorghum production activities. As indicated above $66 \%$ of threshing activity, was done by women and $34 \%$ done by girls, which major value grain value adding activity done by female house hold members.

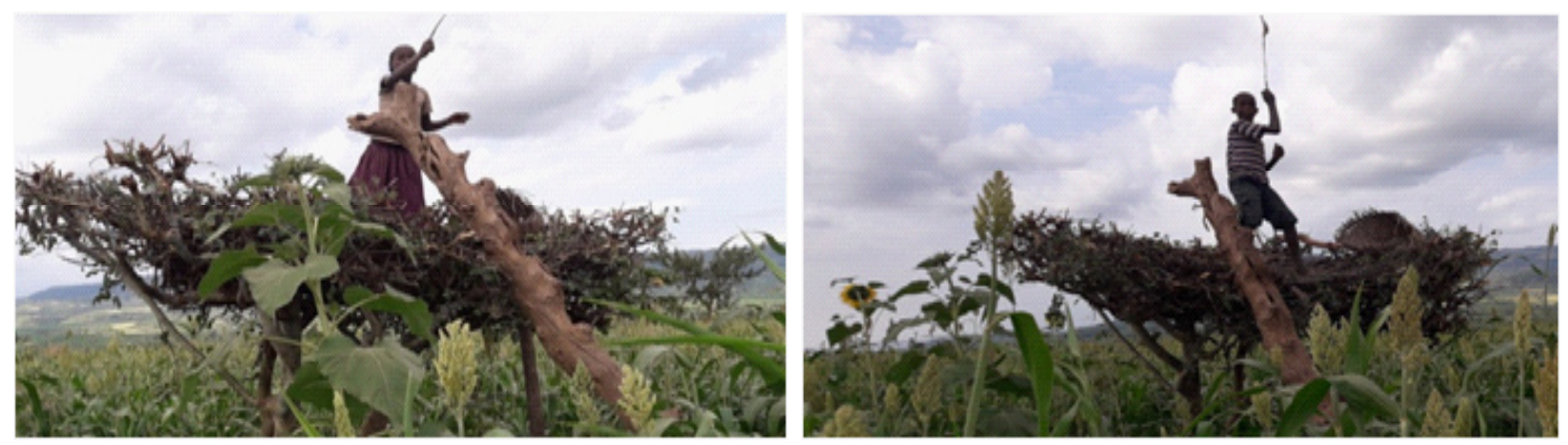

Fig4. Girl and boy at scaring birds
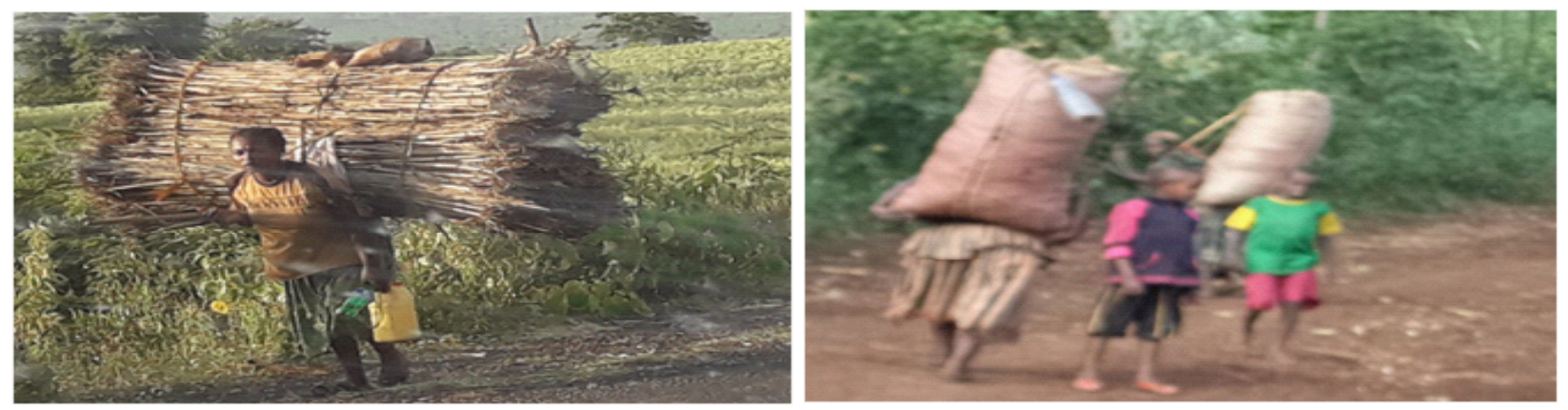

Fig5. (a) Konso woman fetching sorghum stalk and (b) transporting sorghum from field.

2. done using proportional pilling

American Research Journal of Business and Management 
Participatory Gender Analysis of Sorghum Value Chain: the Case of Konso District, Ethiopia Implication for Sorghum Research Improvement

As indicated above extension program at Konso district is not inclusive of women, which hinders participation of women in fertilizer application and other new production technologies. Similarly study conducted [5] at Ambo district indicates that females play a more significant role than males in manual weeding, threshing and transportation of farm produce. However, both males and females play equal roles in planting, soil conservation and management, application of fertilizers and herbicides, storage and marketing of farm produce.

The Konso women are very strong and have the capacity of carrying and transporting grain from the fields to the granary. Men in Konso testify that "our women are very strong and hardworking." On average Konso woman can carry $50 \mathrm{~kg}$ - $80 \mathrm{~kg}$ and travel long distance up to $30 \mathrm{~km}-40 \mathrm{~km}$ to granary and then market. As indicated in (Table 1) around $60 \%$ of sorghum transporting is done by female part of the society. Similarly study conducted by [1] stated that female in Ethiopia also contribute to agricultural production and productivity. But, analysis result indicated that female headed households have limited access to and control over resources, which is crucial to effectively and efficiently meeting their strategic and practical needs due to social and cultural biases in the society. There are differences in terms of access to and control over resources and decision-making between these female headed households.

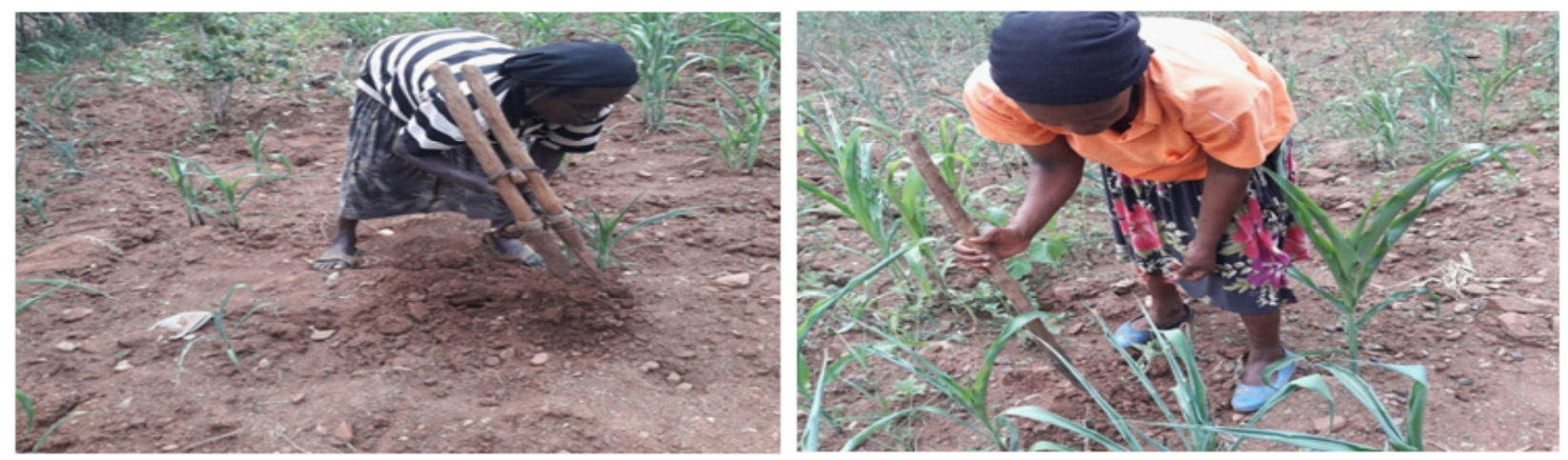

Fig6. Konso woman digging with double-bladed hoe (a) and with single-blade hoe (b)

Table2. Domestic Activities and gender labor contribution

\begin{tabular}{|c|c|c|c|c|}
\hline \multirow{2}{*}{$\begin{array}{c}\text { Reproductive } \\
\text { Reproductive }\end{array}$} & \multicolumn{3}{|c|}{ Labor contribution in gender } \\
\cline { 2 - 5 } & Women (\%) & Girls (\%) & Men (\%) & Boys (\%) \\
\hline Food preparation & 66 & 34 & 0 & 0 \\
\hline Washing utensils & 66 & 34 & 0 & 0 \\
\hline Washing clothes & 0 & 100 & 0 & 0 \\
\hline Child bearing and child rearing & 69 & 31 & 0 & 0 \\
\hline Cleaning house & 66 & 34 & 0 & 0 \\
\hline Building and maintenance & 0 & 0 & 53 & 47 \\
\hline Fetching water & 37 & 63 & 0 & 0 \\
\hline Collecting fire wood & 0 & 100 & 0 & 0 \\
\hline Community management & & & & \\
\hline Committee meeting & 37 & 0 & 53 & 0 \\
\hline Care for elders/ sick persons & 100 & 0 & 0 & 0 \\
\hline Participating in wedding & 20 & 22 & 31 & 27 \\
\hline Participating in funerals & 27 & 13 & 43 & 16 \\
\hline Involvement in village meetings & 40 & 0 & 60 & 0 \\
\hline Involvement in NGO projects & 44 & 0 & 56 & 0 \\
\hline Involvement in political activities & 40 & 0 & 60 & 0 \\
\hline
\end{tabular}

Source: survey result, 2017 
Participatory Gender Analysis of Sorghum Value Chain: the Case of Konso District, Ethiopia Implication for Sorghum Research Improvement

Women in Konso mainly perform the household chores. Apart from farming activity, the primary duties of the women (mother and girls) are to follow the household routines like fetching water (63\% girls and 34\% mother), fire wood (done 100\% by girls), fodder for the cattle, preparing food (66\% mother and $34 \%$ girls) and serve the family. They go to the fields to do farm work spend time there. On the way back

home they collect firewood and fodder for the cattle and go again to the wells to bring water and start to prepare dinner. After serving dinner, they perform the remaining work (Washing utensils, Cleaning house, etc) in the house. The women are always the last to sleep, among the household.

As indicated in (Table 3) women in Konso spend more than 13 hours a day performing the household activities, but men spent around 8 hours a day, but as of agricultural activities are seasonal in the area, work burden of gender varies within cropping season. During off-season both men and women work load decreases and they spent few hours in field work, but still non-remunerative domestic role of women continued throughout the year. In Konso people women job begin from early age- that is at an average of 4 or 5 years by engaging in works like fetching water with small and medium water carrying gourd, looking after the cattle, especially goats and sheep, collecting fire wood and animal fodder. The heavy workload rest on the young girls who are more than 13 years old, adult and elder women.

Table3. Time consumed to perform activities in gender

\begin{tabular}{|c|c|c|c|}
\hline \multicolumn{2}{|c|}{ Women } & \multicolumn{2}{c|}{ Men } \\
\hline Activity & Time in hours & Time in hours & Activity \\
\hline${ }^{1}$ Productive & 5 & 7 & Productive \\
\hline Domestic & 9 & 0 & Domestic \\
\hline${ }^{2}$ Productive & 7 & 0 & Productive \\
\hline Domestic & 8 & 0 & Domestic \\
\hline${ }^{3}$ Productive & 7 & 9 & Productive \\
\hline Domestic & 8 & 0 & Domestic \\
\hline
\end{tabular}

Source: survey result, 2017

\section{Access, Control and Household Decision-Making}

Gender roles in Konso were constrained by an uneven distribution of resources and opportunities between women and men in the household. Where resources are scarce, women (FHHH and polygamy) testify themselves at a greater disadvantaged than the male. Because they (FHHH and polygamy) did not have access to productive resources and training for sorghum production technology. Due to strong believes and taboos women did not participate in village level decision making because in Konso decision is made in meeting place called " Mora" there is believe when women before 45 years old become sterile when she pass through Mora this hinders women from participating in community level decision making. Such believe made only male members decisions maker at the community level. Community works like terrace making, well building, wall maintenance, Mora and house constructing are largely the activities of men. In this time the women are only involved in preparing and providing food and drinks to the workers. Community work and public decision-making activities are areas, in which women do not have an active participation. However, household resource (sorghum) consumption decision, sorghum production, land allocation and input use are made jointly by women and men.

3. Cultural space of Konso located at the center of the main central enclosure and at different locations within the walls, and sometimes outside the walls. Paths from all gates lead to these Moras. Mora is expertly paved to form a public area where the men gather to govern the village life

American Research Journal of Business and Management Page 6 
Participatory Gender Analysis of Sorghum Value Chain: the Case of Konso District, Ethiopia Implication for Sorghum Research Improvement

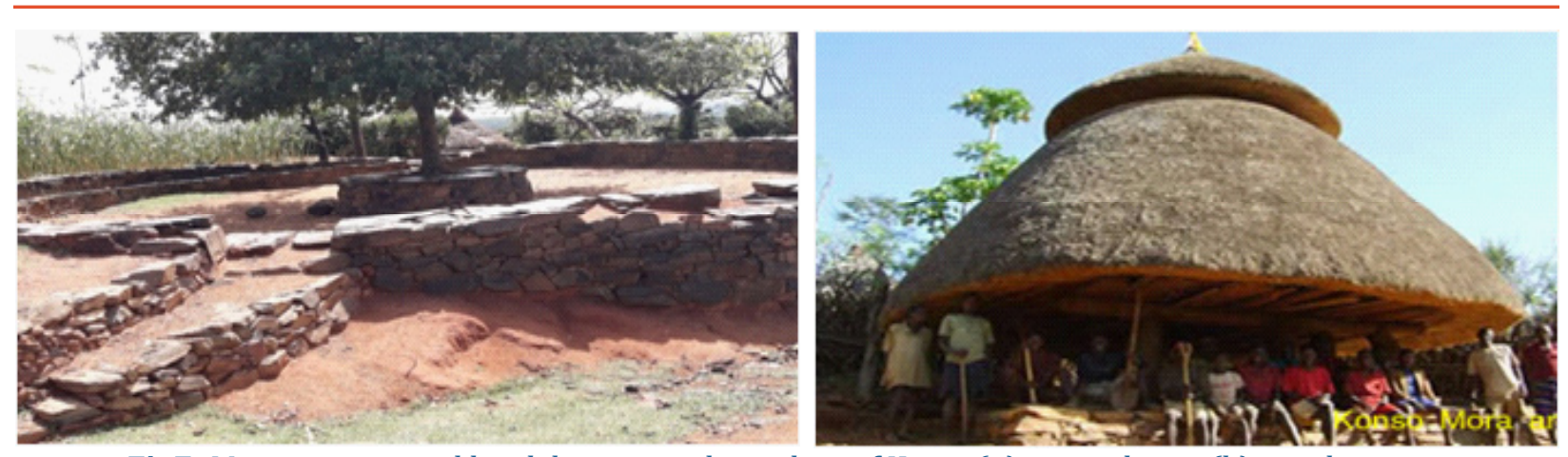

Fig7. Mora meeting and local decision making place of Konso (a) at rural area (b) at urban area

\section{Importance of Sorghum in the Area}

According to FHHH major crops grown based on area coverage sorghum accounts 50\%, maize $25 \%$, Tef $9 \%$, finger millet $8 \%$ and common bean $8 \%$. Comparison of crops importance in terms producer preference of using pair wise ranking shows that preference for sorghum takes first (4), maize is second (3), Tef is third (2) and common bean is fourth.

Table4. Area coverage by different crops

\begin{tabular}{|c|c|c|c|}
\hline \multirow{2}{*}{ Crops grown } & \multicolumn{3}{|c|}{ Proportions of area coverage expressed percentage } \\
\cline { 3 - 4 } & FHHH & polygamy marriage & MHHH \\
Sorghum & 50 & 32 & 35 \\
\hline Tef & 9 & 19 & 19 \\
\hline Maize & 25 & 18 & 14 \\
\hline Figure millet & 8 & 10 & 12 \\
\hline Common bean & 8 & 21 & 20 \\
\hline
\end{tabular}

Source: survey result, 2017

According to polygamy marriage females' major crops grown in the selected kebele based on area coverage are sorghum accounts $32 \%$, maize $18 \%$, common bean $21 \%$, Tef $19 \%$ and finger millet $10 \%$. Their pair-wise ranking analysis result shows that preference for sorghum takes first, Tef is the second and maize is forth important cereal crops of the area.

According to MHHH major crops grown in Konso are sorghum 35\%, common bean 20\%, Tef 19\%, maize 14\% and finger millet $12 \%$. Their pair-wise ranking analysis result shows that sorghum is the most important cereal crop and Tef the second and followed with maize.

According to FGD participants sorghum grain is use in different forms of food items like Cheqa ${ }^{4}$ (local brewer drink made from mixture of $42 \%$ sorghum, $33 \%$ water, $13 \%$ maize and $11 \%$ finger millet, known drink at Segen peoples and South Omo zones), 34\% of sorghum grain is consumed in this form, kurkufa (starch staple meal), $28 \%$ of sorghum grain is consumed in this form, genfo (starch staple meal), $20 \%$ sorghum grain is consumed in this form and qita (unleavened bread), $18 \%$ of sorghum grain is consumed in this form ${ }^{5}$.

4. Unrefined kind of alcoholic beverage prepared from sorghum, brewed in each household about once a week in large quantities. The villagers visit the compound in order to buy and drink the beverage. This is because it is difficult to make in small quantities, but if it is not drunk quickly, it ferments further and loses its flavor.

5. done using proportional pilling 
Participatory Gender Analysis of Sorghum Value Chain: the Case of Konso District, Ethiopia Implication for Sorghum Research Improvement

Also sorghum stalk, leaves and head as fuel sources (sorghum stalk a key fuel for cooking and heating purposes), animal feed (leaf and thin stalk provide nutrition year-round for livestock in the area from its green to dry stages), house construction (use sorghum stalk as component of house construction materials) and house cleaning (sorghum head which remained after grain harvest is used as house cleaning material).

\section{Responses of Women and Men Farmers on Status of Sorghum Production}

According to FHHH and Polygamy marriage females stated that sorghum production trend is increasing and they have put reasons for increasing of sorghum production they said that "sorghum is our major food crop and it is drought resistant crop therefore we allocate large land area for it and relative to other crops sorghum yields high per unit area." Also they intercrop four crops in the same plot of area with different proportions $47 \%$ sorghum, 30\% maize, $12 \%$ common bean and $11 \%$ finger millet. In contrast male headed households stated that sorghum production trend is decreasing and they put reason for decreasing sorghum production.

According to male headed house hold sorghum production is decreasing due to: rain fluctuation and shortage, striga attack, decreasing soil fertility, Land shortage because boys who get married receive plots of land from family and holding for elder family get reduced as a result land allocation for sorghum reduced and sorghum production decreased.

Both men and women agreed up on that the main cultivation tool is a double-bladed hoe and to a certain extent they use oxen. Due to the steep slopes and small terraces ploughing with oxen is challenging, but they cultivate their land using both oxen and double-bladed hoe to plough.

\section{Use of Sorghum Technologies by Women and Men Farmers}

According to focus group participants until 2016/17 crop production season only two varieties (Gubye and Abshir) improve sorghum variety were introduced and around $95 \%$ farmers are using local/land race sorghum varieties and each variety has its own local name like Tishikera, Kembota, uuota, Sulayta, Koyira, Sulayta, Kodhano, Gembella and Atikera, etc, but each variety has their own preference of utilization in addition to food source. For example in addition to food source uuota land race sorghum variety is preference for house construction due to its large stalk size and strength. Almost $100 \%$ focus group participants use broadcasting to plant sorghum and around 58\% use inorganic fertilizer and around 42\% not yet use any fertilizer for sorghum production. Sorghum intercropping is common in Konso and they sow sorghum (36\%), maize (27\%), common bean (23\%) and finger millet $(14 \%)$ in the same plot of land.

\section{Availability of Sorghum for Food and its Copping Mechanism}

As explained by FHHH around all women were not participant of training on sorghum production and did not attend any field day and demonstration. There is no extension worker visit and around $90 \%$ of FHHH get business advice from Omo microfinance agent, but only around $10 \%$ do have access to credit. Male headed households have access to extension information and training.

Almost 100\% FGD participants articulated that they are not food secured and they get high food shortage during April to August and they take the following measures to cope the problems:

$\rightarrow$ Receiving money loan from neighboring relatively rich peoples and buy food items from market especially sorghum.

Sell their livestock and buy sorghum from market

$\checkmark$ Use safety net income as alternative sources for food item purchase. Also when situations become sever government provides food aid.

Collecting firewood from forest and sell it in towns like ${ }^{6}$ Karat and Dhogato

6. Where market places of Konso District

American Research Journal of Business and Management

Page 8 
Participatory Gender Analysis of Sorghum Value Chain: the Case of Konso District, Ethiopia Implication for Sorghum Research Improvement

Hiring at laborers for other farmers and construction work at Karat and Dhogato

Use root crops like cassava as alternative food items.

\section{Gender Factors Identified in Sorghum Value Chain}

Exclusion of Women from Agricultural Extension: the provision of agricultural information, training and advice is way to tackle the barriers that women face in agricultural production and helps women to learn new or improved production techniques. This empowerment in turn leads them to improved income, which promotes their standing in the sector and increases overall food security, but Konso district agricultural extension system lacks doing it correctly. Around $100 \%$ polygamy marriage and female headed households women said that "we are not part of any extension services and trainings including sorghum related technologies" this implies that Konso district extension service is not gender sensitive. Also among focus group participants around $90 \%$ male headed house hold and $100 \%$ female headed and polygamy women do not get any sorghum production related trainings and also male headed households agree up on that women are not included on agricultural extension training and no any training were given for them.

Insufficient Production and Price Fluctuation: surplus production leads producers to have supply to market due to internal and external (lack of access to new sorghum variety, rain fluctuation, striga infestation ...etc) problems both MHHH and FHHH are not producing surplus sorghum which leads them to live with food insecurity. On local markets price for sorghum fluctuated in accordance with the forces of supply and demand. When sorghum were in harvesting season, the price fell, they sorghum in their granaries to some amount and during off season the opposite is true, no sorghum in their granaries while unable to afford it living with hunger and starvation.

Rural Marketing and Credit Problems: credit helps producers to invest in production activities when producers lack money to invest, which fills gap of capital shortages and facilitates surplus production and food security, but needs systematic repay mood and strategies. In case of Konso FHHH and Polygamy women have no access to credit, even if deployed Omo microfinance agent there in kebele administration. Also women are not allowed to sell assets like cattle, sheep, goat and other high pricing cash crops. This leads women's economic subordinate to male and always they wait male decision for high costing household consumptions.

Cultural Taboos and Believe: Culture is one of the constraints to public level decision making for Konso women because community level decision is made at meeting place called Mora, while there is taboo and believe in Konso if women before age 45 be attend meeting and pass through Mora, be cursed and become sterile. Therefore due to fear those believes and taboos women has no any role in community level decision making.

Women Share Abundant Responsibilities and Perform a Wide Spectrum: in Konso sex functions as an organizing principle for society because of the cultural meanings given to being male or female. There are clear patterns of "women's work" and "men's work," both in the household and in the wider community and cultural explanations of why this should be so, but women job is overlapping with male. The general pattern is that women have less personal autonomy, fewer resources at their disposal, and limited influence over community level decision-making processes that shape their societies and their own lives. In general female part of Konso society are over burdened society groups because they perform hardest part of field work what male group perform and tedious work at household chore like, preparing of food in is found to be the most tiresome and time taking activity since it is done in a day to day basis; this responsibility is predominantly shouldered on women, but male group do not support the female part. Therefore, important to describe and appreciate the role of women in reproductive and productive activities.

American Research Journal of Business and Management Page 9 
Participatory Gender Analysis of Sorghum Value Chain: the Case of Konso District, Ethiopia Implication for Sorghum Research Improvement

\section{Priority Problems for Men and Women in Sorghum Production}

Pair-wise ranking of FHHH and polygamy participants response indicates that among listed sorghum production problems rain shortage, striga, long maturity date of sorghum, financial problem, bird-scaring; financial problem (lack of access to credit) takes the first rank (4), rain shortage (3) is the second, striga is the third problem (2) and bird scaring is the least sorghum production problem. Weevil and mice are major sorghum storage problems of the area.

Pair-wise ranking of MHHH participants response indicates that among listed sorghum production problems rain shortage, striga, pest attack and bird-scaring; rain shortage (3) is the first problem, bird-scaring (2) is the second and striga is the third sorghum production problems.

\section{CONCLUSION AND RECOMMENDATION}

Generally, analysis result indicates that the gender division of labor in Konso was rigid and flexible on the basis of types of activities. Accordingly, ploughing with oxen, house construction and maintenance and decision making at community level no female were observed taking these responsibilities indicating that there is rigid gender division of labor. In contrast threshing and winnowing of grains no male farmer was observed taking these responsibilities indicating that there is rigid gender division of labor. In other farm activities like land preparation, weeding, harvesting, bird scaring and transporting both male and female part of the community takes place it reveals that the gender division of labor in these farm task is flexible.

It is believed that agricultural extension services (advices and trainings) are important to enhance farm production and productivity and hence household income. The advices and trainings on crop production in particular included appropriately sowing at the appropriate time and season, importance and use of improved varieties and protecting crops from pests etc were not given for female (both polygamous and FHHH) farmers and they have no access to such services. Majority of these households believed that such services were not fully beneficial to both polygamous and FHHH farm household.

For further improvement focus group participants suggested the following points:

$>$ Provision of trainings on agronomic practice and new sorghum variety

$>$ Provision of striga resistant- early maturing sorghum varieties

> Trainings and extension services should be gender sensitive and women inclusive

$>$ Awareness should be created about cost and benefits of intercropping because almost $100 \%$ sorghum produces farmers sow more than two crops in the same field. From observation and FGD result the following point were recommended by research team:

Reducing Women's Workloads through Introducing Labor Saving Technologies: such as stoves and wheel barrows should be made accessible to women to enable them to manage efficiently their multiple roles and responsibilities. However the technologies need to be tested to ensure applicability within the context

Awareness should be Created on Gender Equality and Women Empowerment: government and nongovernment organizations should continual raise community awareness on gender equality and supporting women empowerment. This will enable men and women to know their rights, and be better able to promote and protect them.

Provision of Nutrition Education and Counseling: In during FGD all the participants mentioned that they do not know about the nutritional value of sorghum and they explained that they consuming it for hunger 
Participatory Gender Analysis of Sorghum Value Chain: the Case of Konso District, Ethiopia Implication for Sorghum Research Improvement

only. Also nutritional value local food items (kurkufa, Cheqa, genfo, etc) made from sorghum should be known and evaluated to help them either they are food secured or not.

Farmers should be Capacitated: all FGD participants explained that the production is only hand to mouse and there is no surplus production therefore they do not supply sorghum to market. Value chain should be developed to help sorghum price fluctuation.

\section{REFERENCES}

1. Addis Tiruneh. 2000. The Missing Link Between Micro and Macro Level Gender Dis-aggregated Economic Data in Economic Policy Formulation and Planning in Ethiopia. Unpublished Paper, Addis Ababa University, Ethiopia.

2. Atlas of Sorghum Production in Eastern and Southern Africa. 2009

3. Bill and Melinda Gates Foundation. 2014. Multi Crop Value Chain Phase II, Ethiopia.

4. Engels, J.M.M.(1990): Konso Agriculture and Its Plant Genetic Resources, Aspect Publishing.

5. Ogato, E. K. Boon and J. Subramani. (2009). Gender Roles in Crop Production and Management Practices: A Case Study of Three Rural Communities in Ambo District, Ethiopia

6. Kathryn Weedman.2004. Gender and Stone Tools: An Ethnographic Study of the Konso and Gamo Hide workers of Southern Ethiopia.

7. Mamitu Yilma (2002). Some Aspects of the Status of Women among the Konso of Southern Ethiopia. Thesis presented to Addis Ababa University

8. Orkaydo Ongaye.2013.Grammar of Konso. PhD. Dissertation Presented to Leiden University.

9. Watson, E.E.(1998): Ground Truths: Land and Power in Konso, Ethiopia, PhD Thesis, Cambridge University, UK.

Citation: Abayneh Feyso, Selamawit Markos, Awoke Mensa. "Participatory Gender Analysis of Sorghum Value Chain: the Case of Konso District, Ethiopia Implication for Sorghum Research Improvement." American Research Journal of Business and Management. 2018; 4(1): 1-11.

Copyright ( $(2018$ Abayneh Feyso, Selamawit Markos, Awoke Mensa. This is an open access article distributed under the Creative Commons Attribution License, which permits unrestricted use, distribution, and reproduction in any medium, provided the original work is properly cited. 